\title{
Spatial Topology Rule Checking Algorithm of Linear Entity Based on Quadtree
}

\author{
Shunping ZHOU, Shaohuai CHEN, Bo WAN \\ China University of Geosciences(wuhan), Faculty of Information Engineering, HuBei WuHan \\ Email: zhouspin@yahoo.com
}

\begin{abstract}
Spatial topology rule is the primary method to insure the consistency and validity of spatial topology relation in GIS software. Topology rule can be divided into three categories according to geographic entity's geometric shape: point topology rule, line topology rule and polygon topology rule. At first, this paper summarizes the various linear geographic entities' topological relations which have practical application, then designs a series of linear entity topology rules detailedly. Based on these rules, this paper proposes a topology rule checking algorithm using quadtree, which is designed on the basis of MAPGIS7.4 spatial data model. The algorithm has already been applied to MAPGIS platform and gained good effects.
\end{abstract}

Keywords: linear entity; topology rule; rule check; quadtree

\section{基於四叉樹的線狀實體拓撲規則檢查演算法}

\author{
周順平，陳少懷，萬 波 \\ 中國地質大學（武漢）資訊工程學院, 湖北 武漢 \\ E-mail: zhouspin@yahoo.com
}

\begin{abstract}
摘 要: 拓撲規則是 GIS 軟體維護地理資料空間拓撲關係一致性和正確性的主要方法。根據地理實體的 幾何形態又可將拓撲規則分為三類：點拓撲規則、線拓撲規則、區拓撲規則。本文首先歸納了有實際 應用價值的各種線狀空間實體拓撲關係，並設計了詳細的線狀實體拓撲規則；然後提出了一種基於四 叉樹的拓撲規則檢查演算法，該演算法以 MAPGIS7.4 空間實體的資料模型為依據，應用於 MAPGIS 平臺並取得良好效果。
\end{abstract}

關鍵字：線狀實體；拓撲規則；規則檢查；四叉樹

\section{1. 前 言}

空間實體的拓撲關係是地理資訊系統（GIS）研 究的核心問題之一, 是 GIS 進行空間分析、空間決 策支持的基礎。然而, 資料被創建的時候, 可能没 有建立拓撲關係或者存在錯誤的拓撲關係; 資料被 修改的時候，原有的空間拓撲關係可能會被破壞。 拓撲規則正是為了解決這一問題而產生的。它通過 對資料空間進行拓撲關係檢查, 找出不符合用戶所
定義的拓撲關係的資料，可以很好地維護錯綜複雜 的拓撲關係，對於保證空間資料的正確性、一致性 和完整性具有重要的意義, 是 GIS 提高資料品質的 一個重要途徑。

四叉樹是一種結構清晰、容易建立的層次型資料 結構, 它具有聚集空間目標的能力, 可以改善空間檢 索的性能，因此被廣泛地應用於空間索引之中。本文 以 MapGIS7.4 線狀空間實體的資料模型為基礎，提出 了線狀空間實體的拓撲規則管理機制，並詳細介紹了 
基於四叉樹的線狀實體空間拓撲規則檢查演算法的設 計與實現。

\section{2 線狀實體空間拓撲規則的設計}

地理資訊系統以空間實體為物件, 這些物件在電 腦中用圖形的方式將其表現出來。地理實體之間有一 定的空間關係，如鄰接、連通、臨近和重疊等關係。 在圖形學上, 這些不考慮度量和方向的空間實體之間 的關係稱為拓撲關係。Egenhofer 和 Franzosa (1991) 提出的“九交模型”論證了 19 种具有實際意義的拓撲 關係：點對點的相離、共位、相鄰、包含; 點對線的 相離、相鄰、相交、包含; 點對區的相離、相鄰、包 含; 線對線的相離、相鄰、相交、共位; 線對區的相 離、相鄰、相交、包含; 區對區的相離、相鄰、相交、 包含。線狀實體拓撲關係主要描述線要素之間鄰接、 關聯、相交、共用邊界等空間關係，所以線拓撲規則 主要限制了線要素和線要素之間不能相交或重疊、線 要素自身不能自相交或自重疊以及不能有“懸點”等拓 撲關係。

在實際應用中, 不僅需要在一個要素類內部建立 拓撲規則, 不同的要素類之間也需要建立拓撲規則來 約束拓撲關係。一般地, 在一個要素類內部建立的拓 撲規則被稱為一元拓撲規則, 在兩個要素類之間建立 的拓撲規則被稱為二元拓撲規則。筆者設計的線狀實 體一元拓撲規則和二元拓撲規則見表 1 。

\section{2. 基於 MAPGIS7.4 的線狀實體空間拓撲規 則檢查演算法}

\subsection{MAPGIS7.4 線狀空間實體資料模型}

MAPGIS7.4提出了一種新的資料模型—一面向實 體的空間資料模型。在面向實體空間資料模型中，空
間實體被抽象為要素，相同類型的要素構成要素類。 在MAPGIS7.4設計的要素類模型中，一個要素表示一 個獨立的實體，不存儲拓撲資訊。要素的類型也是通 過幾何形態進行約束, 要素的類型有多點、線、多線、 多邊形和多多邊形五種。對於每一種類型的要素, 其 資料結構都直接由座標組成。以線狀空間實體為例, 其資料結構的組織形式為:

\begin{tabular}{l|l|l|} 
ID & 座標點數 & 座標資料 $(\mathrm{X} 1, \mathrm{Y} 1, \mathrm{X} 2, \mathrm{Y} 2, \ldots \ldots, \mathrm{Xn}, \mathrm{Yn})$ \\
\hline
\end{tabular}

\section{2 四叉樹基本思想}

四叉樹索引是建立在對區域迴圈分解原則之上 的一種層次資料結構, 在電腦圖形處理、圖像處理及 地理資訊系統中有著廣泛的應用。四叉樹索引的基本 思想是：把資料空間分成4個一級子塊; 然後比較此4 個子塊的屬性值, 若完全相同, 則不再分割; 若不同, 則將子塊進一步分成4個二級子塊, 再進行比較; 如此 遞迴地分割，直到每個子塊的屬性相同為止，最後得 到一棵四分叉的倒立的樹。

按照空間劃分方式，四叉樹可分為兩類:點四叉 樹、區域四叉樹以及 CIF(Caltech Intermediate Form) 四叉樹。CIF 四叉樹是針對表示 VLSI (Very Large Scale Integration)應用中的小矩形而提出的, 它可以用 於索引空間矩形及其它形體。採用 CIF 四叉樹索引結 構時, 資料空間被遞迴地細分直至產生的子象限不再 包含任何矩形。在分解的過程中，所有與任一劃分線 相交的矩形與該劃分線對應的象限相關聯，屬於一個 象限的矩形不能屬於任何祖先象限，也就是說，矩形 只屬於完全包圍它的最小象限。下圖 1 是一顆 CIF 四 叉樹的例子。

表 1. 線狀實體空間拓撲規則詳細資訊

\begin{tabular}{|c|c|c|}
\hline 類別 & 拓撲規則類型 & 拓撲規則描述 \\
\hline \multirow{8}{*}{ 一元 } & 線 & 一個要素類內部, 線必須是單一連續的 \\
\hline & 線 & 一個要素類內部，線不能有“懸點” \\
\hline & 線 & 一個要素類內部，線和線之間不能重疊 \\
\hline & 線 & 一個要素類內部, 線不能自重疊 \\
\hline & 線 & 一個要素類內部，線和線之間不能相交 \\
\hline & 線 & 一個要素類內部, 線不能自相交, 不能自重疊, 可以接觸 \\
\hline & 線 & 一個要素類內部, 線和線之間不能相交或重合, 只能線上的端點接觸 \\
\hline & 線 & 一個要素類的線不能和另一個要素類的線重疊 \\
\hline \multirow{3}{*}{ 二元 } & 線 & 一個要素類的線必須被另一個要素類的線覆蓋 \\
\hline & 線 & 一個要素類的線的端點必須被另一個要素類的點覆蓋 \\
\hline & 線 & 一個要素類的線必須被另一個要素類的區邊線所覆蓋 \\
\hline
\end{tabular}




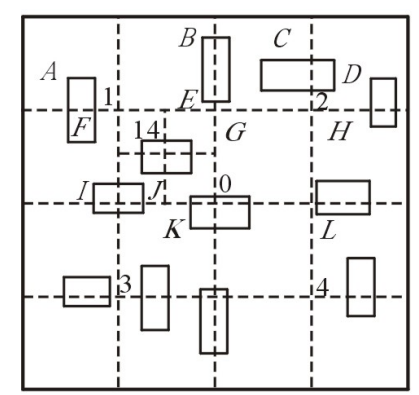

(a)

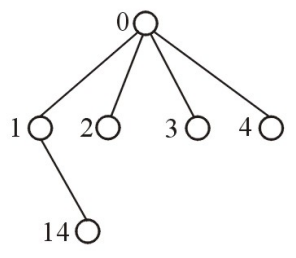

(b)

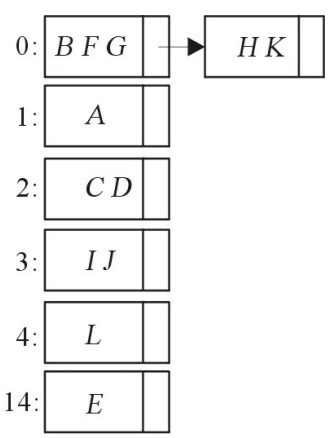

(c)

圖 1. CIF 四叉樹

CIF匹叉樹可以用於索引矩形以及任何其他形體 的空間目標, 但是不需要經過目標近似與空間目標映 射。因此, 對於區域查詢, 效率較高。下面筆者將介 紹基於CIF四叉樹的線狀實體拓撲規則檢查演算法的 實現。-

\section{3 演算法的設計與實現}

MAPGIS線要素是由一串座標點組織而成, 相鄰 的兩個點連接成一個線段, 所有線段依次連接成為折 線。基於四叉樹的拓撲規則檢查的思想是, 遍歷數據 空間中所有的線要素, 對於每一個線要素, 將組成該 線要素的線段作為空間物件, 添加到四叉樹中, 形成 一個以線段為空間單位的四叉樹。然後再次遍歷數據 空間的線要素, 以組成線要素線段的矩形範圍在四叉 樹上做檢索, 查詢出可能與該線段矩形範圍相交的所 有其他線段的集合。最後根據定義的規則來判迦線段 之間的關係。

\subsection{1 資料結構}

對於上述CIF四叉樹索引，其資料結構包括空間 物 件（ LineSeg）、樹節 點 (QuadTreeNode) 和 樹 (QuadTree)。資料結構如下所示:

typedef struct \{

$\begin{array}{lll}\text { _int64 } & \text { id; } & \text { //要素ID } \\ \text { _int64 } & \text { segid; } & \text { //線段在要素中的序號 } \\ \text { D_DOT } & \text { dot1; } & \text { //線段的起始點 } \\ \text { D_DOT } & \text { dot2; } & \text { //線段的終止點 }\end{array}$

\} LineSeg; typedef struct QuadTree_node \{ D_RECT rect; //該節點所覆蓋的矩 形區域範圍 long level; //該節點的層次編碼 vector $<$ LINESEG $>$ item; //存儲在這個節點中 的所有空間物件集合

QuadTree_node *subnode[4]; //嵌套定義的樹節點 鏈表結構,表示此節點擁有4個子節點

\} QuadTreeNode;

\subsection{2 結點編碼}

四叉樹結點編碼能惟一標識構成資料空間的各子 區域. 對四叉樹的每個節點編碼, 結點的位置通過覆 蓋該節點的空間物件以及其子節點空間物件的矩形, 以及該矩形的層次來表示。

對於給定的空間區域 $\mathrm{R}$, 將 $\mathrm{R}$ 分割成 $2 \mathrm{nX} 2 \mathrm{n}$ 個小方 格，如圖1所示。四叉樹葉節點的矩形對應每個小方 格。子結點的層次和子結點的矩形相對應。子節點的 層次碼為

$$
\text { level }=\log 2 \mathrm{D}(\text { rect })
$$

式中level為子節點的層次碼, $\mathrm{D}(\mathrm{rect})$ 為子節點的 矩形寬度。

\subsection{3 四叉樹節點插入演算法}

假設已經為一組空間物件創建好四叉樹索引，現 將空間物件線段 $\mathrm{AB}$ 插入到四叉樹索引中。演算法如 下:

Step1: 根據根結點的矩形資訊, 計算根結點矩形 的中心點。以中心點來計算軸線, 判斷線段 $\mathrm{AB}$ 與軸線 的關係。如果線段 $A B$ 與軸線相交, 則將線段 $A B$ 插入 到根節點的空間物件集合中, 插入完成; 否則, 判斷 線段屬於哪一象限，得到該線段屬於哪一個子結點。

Step2:判迦子節點是否為空, 如果為空, 則創建 一個子節點, 加入至四叉樹索引中, 插入完成; 如果 子結點不為空, 則判斷子節點的矩形是否包含了線段 $\mathrm{AB}$ 的外包矩形。如果是則轉入step4, 否則轉入step 3 ; 
Step3：創建一個新子結點, 該子結點的矩形範圍 包含原來子結點的矩形範圍以及線段 $\mathrm{AB}$ 的外包矩 形，將原來的子結點作為新創建的子結點的一個子結 點，並新創建的子結點來替換原來的子結點。

Step4：以子結點作為新的根節點，返回Step1。

\subsection{4 四叉樹的查詢演算法}

四叉樹的查詢是根據給出一個指定的矩形大 小, 檢索出可能與該矩形相交的所有空間物件。演算 法如下:

Step 1: 判㫁根結點是否為空, 如果根結點為空, 則直接返回; 如果根結點不為空, 則將根結點中存儲 的空間物件添加到返回結果中;

Step 2: 判斷給定的矩形範圍屬於當前根結點的哪 一個象限, 得到與該象限相關聯的子結點。如果該矩 形與坐標軸相交，則直接返回;

Step 3：以子結點為新的根結點, 返回Step 1 。

\subsection{5 基於四叉樹的拓撲規則檢查演算法}

基於四叉樹的拓撲規則檢查演算法如下:

Step 1: 取出資料空間的所有線要素, 對於每一個 線要素, 取出組成線要素的座標點的集合, 相鄰的兩 個點組成一條線段, 將線段資訊添加到四叉樹索引中。

Step 2: 依次遍歷數據空間的線要素, 以組成線實 體的線段外包矩形在四叉樹中進行查詢, 檢索出可能 與該線段相交的所有線段集合。

Step 3: 依次判斷該線段和查詢結果集中的線段的 拓撲關係，根據線段之間的拓撲關係從而得出線段所 線上要素之間的拓撲關係。

Step 4. 將定義在該要素類上的拓撲關係與檢查出 來的拓撲關係相比較, 如果違反了在該類上定義的規 則，則將該要素添加到錯誤結果集合中。

Step 5: 返回Step 1, 如果已經遍曆完資料空間中 所有的要素, 則檢查完成;

\section{3. 演算法性能分析}

首先分析算怯的時間複雜度。由上可知, 本演算 法的實現大致可分為兩步: 首先, 根據線段的外包矩 形計算鄰接網格單元並將鄰接網格單元轉化為四叉樹 的葉結點; 然後, 根據線段的外包矩形在四叉樹中查
詢出可以與其相交的線段集合。在演算法實現的第一 步中, 增設了結點層次編碼，雖然增加了存儲開銷， 但是標識了不同結點的之間的網格大小關係，加快了 結點的插入速度。在演算法實現的第二步中, 根據四 叉樹索引結構可以進行四分查找，在查詢過程中，四 叉樹的深度即為最大比較次數。

其次分析拓撲規則檢查結果的完整性。首先，本 演算法在查詢過程中，不僅將與矩形查詢範圍相交的 結點的空間物件加入到查詢結果中，而且將所有父節 點的空間物件集合都加入到查詢結果中, 保證了查詢 結果的完整性;其次, 本演算法利用組成線實體的線段 之間的關係來判斷線實體之間的關係，保證了檢查結 果的完整性。

\section{4. 結束語}

空間拓撲規則的引入對維護地理資料庫空間資料 拓撲關係的正確性和一致性有非常重要的作用。本文 針對MAPGIS7.4面向實體的空間資料模型，提出了一 種基於四叉樹的規則檢查演算法，該演算法具有聚集 空間目標的能力, 同時大大改善了空間檢索的效率。 但是該演算法仍需進一步改進，例如，四叉樹層次過 大時, 將導致重複存儲的增加, 從而增加空間開銷, 同時也會影響查找效率。今後還需在大資料量的規則 檢查方面繼續深入探索和研究。

\section{參考文獻 (References)}

[1] 吳信才. 地理資訊系統原理與方法 [M]. 北京: 電子 工業出版社, 2002.

[2] 周順平，李華，等. 空間實體的拓撲構建 [J]. 中國地 質大學學報, 2006, 31(5): 590-591.

[3] 葉亞琴, 左澤軍, 等. 面向實體的空間資料模型 [J]. 中國地質大學學報, 2006, 31(5): 595-599.

[4] 陳軍，劉萬增，等. 線目標間拓撲關係的細化計算方法 [J]．測繪學報, 2006, 35(3): 255-260.

[5] 蔡曉兵. Geodatabase 中基於規則的拓撲關係管理機制 [J]. 資訊技術, 2002, 4, 40-43.

[6] S. Shekhar and S. Chawla 著, 謝昆青, 馬修清, 等譯. 空 間資料庫 [M]. 北京: 機械工業出版社, 2004.

[7] M. J. Egenhofer and R. D. Franzos. Point-set topological spatial relations [J]. Journal of GIS, 1991, 5(2). 